\title{
Diffusion-Weighted Image in Correlation with T2 Sequence as an Imaging Biomarker for Urinary Bladder Cancer
}

\author{
NANCY M. ABD EL-NOUR, M.Sc.; RASHA S.A. HUSSEIN, M.D. and SAHAR AL-GAAFARY, M.D. \\ The Department of Radiology, Faculty of Medicine, Ain Shams University
}

\begin{abstract}
Background: Recent functional diagnostic imaging techniques have emphasized the role and importance of MRI in pelvic organs imaging. Functional imaging by means of Diffusion-Weighted Magnetic Resonance Imaging (DW-MRI) and ADC value are now considered an essential part of the standard imaging protocols for evaluation of the pelvic organs.

DWI depends on the fact that water molecules can diffuse freely in low cellular tissues, while increased cellularity restricts its diffusion, a phenomenon called 'Brownian motion'. Therefore, in cases of malignant lesions which have high cellularity, water diffusion is restricted and appear as bight lesions, in contrary to most benign tumors which have low cellularity.

Aim of Study: To assess the diagnostic value of DWI in correlation with T2WI for preoperative urinary bladder tumor T-staging.

Patients and Methods: This is a prospective study that included twenty-six patients with hematuria and suspicious urinary bladder mass lesion on ultrasonography, age ranged from 54 to 70 years old, 22 patients were male while 4 were female. The patients were referred from the Urology Clinics, Ain Shams University, before cystoscopy and initial biopsy confirmation. MRI examination with DWI and T2WI was performed at the Radiology Department of Ain Shams University Hospital in a period of 6 months from January to June 2018.

Results: In this study, 24 patients were confirmed to have urinary bladder cancer while one patient had nonspecific inflammatory reaction and another patient had infiltrating prostatic cancer. Regarding the detection of urinary bladder carcinoma the overall sensitivity, specificity, and accuracy using T2 images alone were 71.8, 73.2 and $72.4 \%$, respectively, using DWI alone were $87.8,87.8$ and $88 \%$, respectively and by using T2 plus DWI images were $87.8,95.5$ and $91.6 \%$, respectively. The ADC value of $0.8 \times 10^{-3} \mathrm{~mm}^{2} / \mathrm{sec}$ was found to be a cut off value for differentiating low grade tumors (grade I-II) from high grade tumors (grade III) with sensitivity, specificity and accuracy of $71,55.5$ and $65 \%$ respectively.
\end{abstract}

Correspondence to: Dr. Nancy M. Abd El-Nour, The Department of Radiology, Faculty of Medicine, Ain Shams University
Conclusion: DWI has several advantages that can provide information regarding the lesion's size, number, location, local staging. The estimation of ADC value helps to predict the tumor nature and grade. The sensitivity and accuracy of DWI is higher when correlated with $\mathrm{T} 2 \mathrm{WI}$, which greatly help in guiding the surgeons performing conventional cystoscopy.

Key Words: Urinary bladder carcinoma-Staging of urinary bladder cancer-Diffusion weighted MRI-ADC value.

\section{Introduction}

URINARY bladder cancer is the second most common cancer of the genitourinary system [1] with Transitional Cell Carcinoma (TCC) being the most common type [2].

Cystoscopy with biopsy is still the gold standard tool for bladder cancer staging [3]. However, limitation in detection of flat lesions and lack of the assessment of extra-vesical tumor invasion represent the main drawbacks [4].

Magnetic resonance imaging is the modality of choice in imaging bladder tumor. Diffusion Weighted Imaging (DWI) can delineate pathologic lesions with high tissue contrast against generally suppressed background signal [5] and provides useful information about $\mathrm{T}$ staging of bladder cancer [6]

\section{Aim of study:}

The aim of this work is to assess the diagnostic value of DWI in correlation with T2WI for preoperative urinary bladder cancer T-staging.

\section{Patients and Methods}

The Ethical Committee of Faculty of Medicine, Ain Shams University, approved the study and signed informed consent was obtained from all participants. This prospective study included 26 
cases, age ranged from 54 to 70 years old with mean age $62( \pm 8 \mathrm{SD}), 22$ patients were males while 4 were females. All were referred from the Urology Clinics, Ain Shams University in a period of 6 months from January to June 2018, before cystoscopy and initial biopsy confirmation to the Radiology Department of Ain Shams University Hospital.

Inclusion criteria: Adult patients (males and females) with no age predilection who presented with gross hematuria and underwent pelvic ultrasonography, showing suspicious urinary bladder mass lesion, were included.

Exclusion criteria: Contraindications to MRI (i.e. metallic implants) and patients who received chemotherapy or radiotherapy before scanning.

Methods: All cases were subjected to full history taking with special emphasis on age, residency, occupation and special habits e.g. smoking, history of long-term catheterization.

Patient preparation:Adequate bladder filling with no special bowel preparation was required.

Method of diagnosis: All patients were diagnosed and staged by histopathology analysis in different histopathology laboratories.

MR imaging protocol: MR imaging was performed using a 1.5-TMR Imaging Unit (Achieva, Philips Healthcare, Best, the Netherlands). All the patients were imaged in the supine position, head pointing to the magnet (HFS) using a high resolution 16 channel (Torso) coil. For optimal evaluation of the pelvis, T2WI images were taken in 3 planes: Axial, coronal and sagittal. Axial oblique DWI was performed applying three different $b$ factors of 0,400 , and $800 \mathrm{~s} / \mathrm{mm}^{2}$. T2-weighted images were obtained (repetition time msec/echo time msec, 4303/115; matrix, 264 X 250; section thickness, $5 \mathrm{~mm}$; intersection gap, $0.5 \mathrm{~mm}$; field of view, $270 \times 327 \mathrm{~mm}$ ). Then, DW images were obtained in the axial plane (repetition time msec/echo time msec1633/62; matrix, 112 X 84; section thickness, $5 \mathrm{~mm}$; intersection gap, $0.5 \mathrm{~mm}$; field of view, 340 $\mathrm{X} 255 \mathrm{~mm}$. ADC maps were generated and ADC values were me-3asured at the Region of Interest (ROI) in $\left(\mathrm{X} \mathrm{10}^{-3}\right)$ millimeters squared per second.

Image analysis: MR images were reviewed and evaluated apart from the histopathology results according to the updated staging system of the American Joint Committee on Cancer in 2017 [7]

On conventional MRI sequences; urinary bladder carcinoma (later confirmed by histopathology analysis) which is superficial or papillary tumors is isointense to detrusor muscle on T1-weighted images and of lower signal intensity than urine on T2-weighted images, in which the layer of detrusor muscle is uninterrupted. In patients with muscleinvasive tumor, the low signal intensity of the detrusor muscle is interrupted by the tumor. In patients with extravesical disease spread, a clear extravesical mass can be seen in stage T3b disease, and adjacent organ invasion can also be visualized in stage $\mathrm{T} 4$ disease.

On DWI; Stage T1 or lower: Tumor appears as a high SI mass with or without a submucosal stalk, or just high SI thickening of the wall, Stage T2: when there is no low SI layer representing the submucosal stalk, but the tumor margins are still regular, Stage T3: When there is invasion to the extra-vesical fatty tissue and the tumor margins are serrated or spiky and Stage T4: When there is infiltration into the nearby pelvic organs [6].

In addition to the detection of bladder cancer [8], DWI helps in bone metastasis and by using ADC value there is an ability to characterize histopathology features [9], detection of lymph node metastasis [10] and predicting metastasis potential [11].

On the other hand, because of limited spatial resolution and technical artefacts, DWI may have limitations in detecting all lymph nodes metastasis [10], bone metastasis [12] and underestimation of the tumor stage.

Statistical analysis: Data entry and Statistical Analysis were done using (R Version 3.5.3 for windows with loaded ROSE 0.0-3 package) and Microsoft excel 2013 for generating the ROC curve and calculating Area Under the Curve (AUC). The following measures were then calculated: Sensitivity, specificity, PPV, NPV, accuracy and confidence interval by using online software package Med Calc Version 14.12.0.

\section{Results}

\section{Patients characteristics:}

This study included 24 patients, the patients' age ranged from 54 to 70 years old with mean age $62( \pm 8 \mathrm{SD})$. Eighty-four percent of patients were smokers and $11.5 \%$ had associated bilhariziasis. Urothelial carcinoma represented $53.5 \%$ of cases (non-muscle invasive urothelial carcinom in $11.5 \%$ and muscle invasive urothelial carcinoma in $42 \%$ ), squamous cell carcinoma in $15 \%$, non-specific inflammatory reaction in $3.8 \%$ and prostatic adenocarcinoma in $3.8 \%$. 
The ADC values ranged from 0.09 to $1.6 \mathrm{X}$ $10^{-3} \mathrm{~mm}^{2} / \mathrm{s}$ (mean $\left.0.68 \times 10^{-3} \pm 0.4 \mathrm{SD}\right)$.

The difference in mean ADC values between low grade tumors and high grade tumors is statistically significant being $(p<0.05)$. The ADC value of $<0.8 \times 10^{-3} \mathrm{~mm} / \mathrm{sec}$ was found to be a cut off value for differentiating low grade tumors (Grade I-II) from high grade tumors (Grade III). The ADC values of tumors of squamous cell origin tend to be less than $0.1 \times 10^{-} \mathrm{mm} / \mathrm{sec}$. There was significant difference between the mean ADC value of tumors of Grade I and III ( $p=0.002)$; and between Grade I and II ( $p=0.001)$. However, there was less significant difference between Grade II and III ( $p=$ $0.90)$.

In this study, the sensitivity, specificity and accuracy of T2WI alone in detecting $\leq \mathrm{T} 1-\mathrm{T} 2$ and T3-T4 stages were 66.7, 75, 70.8\% and 77, 71.4, $74.1 \%$ respectively. The sensitivity, specificity and accuracy of DWI alone in detecting $\leq \mathrm{T} 1-\mathrm{T} 2$ and T3-T4 stages were 83.3, 92.3, 88\% and 92.3, 83.3, $88 \%$ respectively. The sensitivity, specificity and accuracy of T2WI plus DWI in detecting $\leq \mathrm{T} 1-\mathrm{T} 2$ and T3-T4 stages were 83.3, 100, 91.6\% and 92.3, $91,91.6 \%$ respectively.

The overall sensitivity, specificity and accuracy in detecting $\leq \mathrm{T} 1-\mathrm{T} 2$ and $\mathrm{T} 3-\mathrm{T} 4$ stages were as follows (Table 1).

Regarding the nodal stage: Overall sensitivity, specificity, accuracy was $66.3,82,77 \%$ by T2 alone, $63.2,82.4,76 \%$ by DWI alone and 63.2 , $78.3,73 \%$ by $\mathrm{T} 2$ plus DWI.

A 70-year-old female patient, ex-smoker, presented to the urology clinic with hematuria and pyouria Fig. (1).

A 61-year-old male patient, Shisha smoker and working as a plumber, presented to the urology clinic with mild hematuria and urgency Fig. (2).

A 69-year-old male patient presented to the urology clinic with long duration of hematuria, pelvic pain, weight loss and back pain Fig. (3).
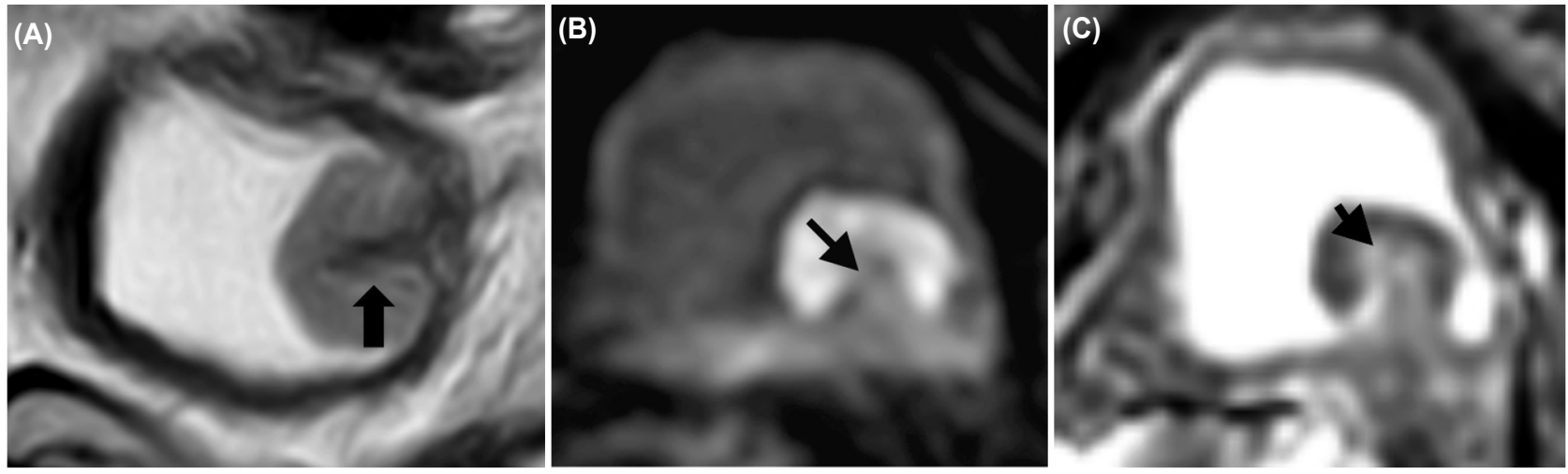

Fig. (1): (A) Sagittal T2WI shows the lesion with an internal hypointense linear core (arrow). (B,C) Axial DWI and ADC map respectively clearly shows the creeping inchworm sign of stage $\mathrm{T} 1$ tumors as a $\mathrm{C}$-shaped superficial layer of restricted diffusion and facilitated diffusion of its central stalk connecting it to the underlying submucosa similar to the archlike shape of an inchworm. Its ADC value was $0.1 \times 10 \mathrm{~mm} / \mathrm{sec}$. Pathology analysis confirmed tumor stage pT 1 and revealed low grade invasive papillary urothelial carcinoma invading only the lamina propria.
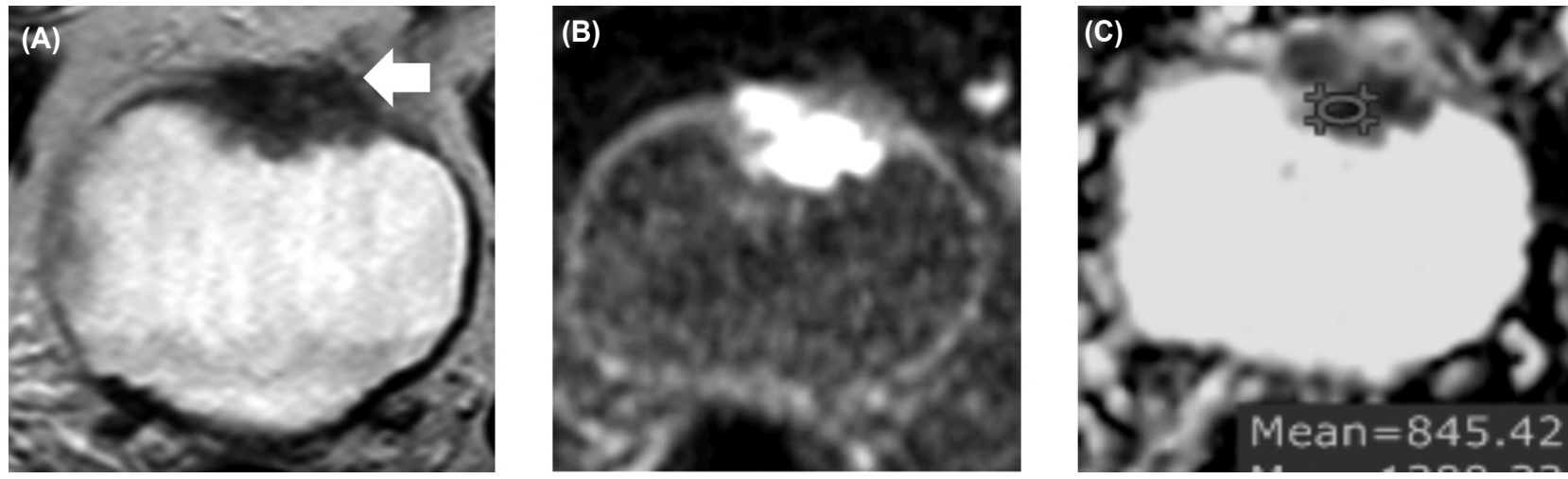

Fig. (2): (A) Axial T2WI shows hyperintense lesion with interruption of the hypointense muscle and smudging of the anterior perivesical fat planes (white arrow). (B) Axial DWI shows restricted diffusion and (C) ADC map shows ADC value of $0.8 \times 10 \mathrm{~mm} / \mathrm{sec}$. Histopathology revealed invasive high grade urothelial carcinoma invading muscularis propria associated with bilharziasis. 

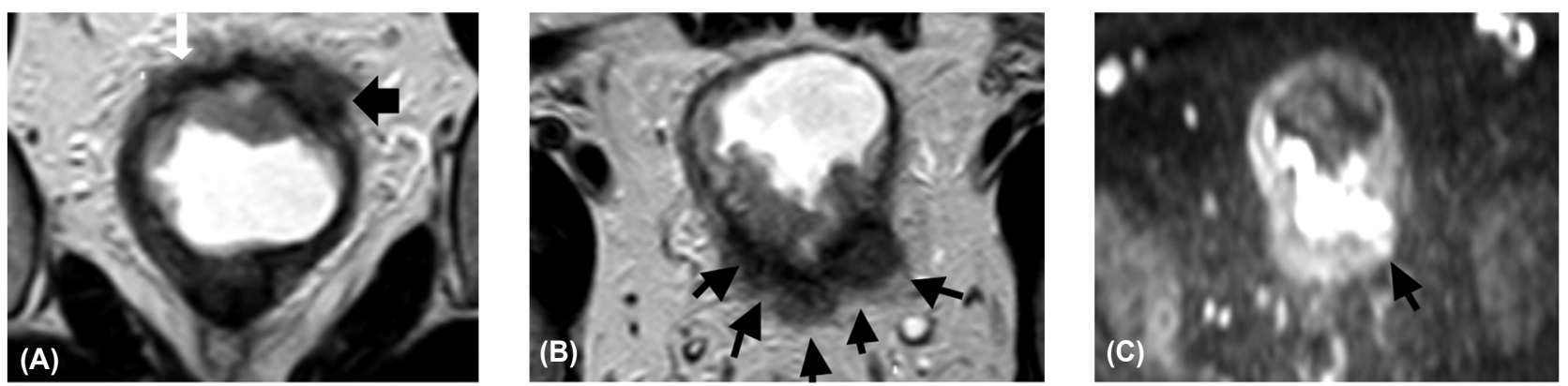

Fig. (3): (A) Coronal T2WI shows a slightly hyperintense lesion which also extends to the dome where it interrupts the hypointense line of the muscle (white arrow) and causes fuzziness of the surrounding fat planes as well (black arrow), (B) Axial T2 WI shows smudging of the posterior fat planes (arrows) and (C) It shows restricted diffusion on axial DWI and better demonstration of invading through the left posterolateral wall of the urinary bladder (arrow). Its ADC value was $0.57 \times 10^{-3} \mathrm{~mm}^{2} / \mathrm{sec}$. The histopathology result reported invasive high grade urothelial carcinoma with prominent lympho-vascular emboli.

Table (1): Overall sensitivity, specificity and accuracy of T2WI alone, DWI alone and T2WI plus DWI.

\begin{tabular}{lccc}
\hline Overall results & Sensitivity & Specificity & Accuracy \\
\hline Overall T2 & $71.8 \%$ & $73.2 \%$ & $72.4 \%$ \\
Overall DWI & $87.8 \%$ & $87.8 \%$ & $88 \%$ \\
Overall T2 plus DWI & $87.6 \%$ & $95.5 \%$ & $91.6 \%$ \\
\hline
\end{tabular}

\section{Discussion}

Transitional cell-origin type is considered the most commonly encountered bladder cancer [2] Accurate differentiation between non-muscle invasive and muscle invasive bladder cancer is essential [9].

The application of MRI conventional techniques namely T2WI has added to the accuracy of detection and staging of urinary bladder cancer. According to our results the sensitivity, specificity and accuracy of using T2WI alone were 71.8, 73.2 and $72.4 \%$, respectively. While, Al-Assmy et al., [8] study which involved 104 patient and showed an overall T2 accuracy as low as 39\% due a frequent study error of over-staging of organ-confined tumors. According to our study the accuracy of T2WI images alone in differentiating organ confined from non-organ confined is $72 \%$ may be due to applying less slice gap. According to Takeuchi et al., [6], DWI has high accuracy and specificity due to its ability to differentiate urinary bladder wall layers and detect muscle layer invasion. Our analysis of DWI alone revealed an overall sensitivity, specificity and accuracy of $87.8,87.8$ and $88 \%$, respectively. Al-Johi et al., [14] study reported that the overall sensitivity and accuracy of DWI alone was $100 \%$. In our study, the accuracy of differentiating organ confined from non-organ confined is $84.6 \%$ by using DWI alone may be due to usage of lower b values. Also, in our current work, we studied the advantage of T2WI plus DWI, and the overall sensitivity, specificity and accuracy were 87.8, 95.5 and $91.6 \%$, respectively. Al-Johi et al., [14] study reported sensitivity and accuracy of T2 plus DWI being 100 and $68.5 \%$ respectively with an accuracy more than T2 (63\%) but less than DWI $(100 \%)$ may be due to usage of higher $b$ values. In our study, the accuracy of T2 plus DWI in differentiating organ confined from non-organ confined tumors is $84.6 \%$. Similar results are reported by Al-Johi et al., [14] who reported an accuracy of $83 \%$ which is better than $\mathrm{T} 2$ alone (75.9\%) and DWI alone (77.4\%).

In this study, we also evaluated the application of ADC value in differentiating high grade tumors from low grade tumors. There was significant difference between the mean ADC value of tumors of Grade I and III ( $p=0.002)$; and between Grade I and II $(p=0.001)$. However, there was less significant difference between Grade II and III $(p=0.90)$. The ADC value of $0.8 \times 10^{-3} \mathrm{~mm}^{2} / \mathrm{sec}$ was found to be a cut off value for differentiating low grade tumors (Grade I-II) from high grade tumors (Grade III) as showed in our case (No. 2) Fig. (2C). Our results came in agreement with those of several studies as Wang et al., [15], who reported an ADC cutoff value of $0.89 \times 10^{-3} \mathrm{~mm}^{2} / \mathrm{sec}$ with sensitivity ranging from 88 to $100 \%$ and specificity from 85 to $95 \%$.

Regarding the assessment of nodal staging by MRI, T2WI showed a higher sensitivity, specificity and accuracy than DWI or even when correlated with DWI.

In conclusion, adding diffusion-weighted image to T2WI increases the accuracy of pre-operative staging and can help in evaluating the urinary bladder tumor's grade through the estimation of $\mathrm{ADC}$ values. 


\section{References}

1- LOPEZ-BELTRAN A.: Bladder cancer: Clinical and pathological profile. Scandinavian Journal of Urology and Nephrology, 42 (Sup. 218): 95-109, 2008.

2- FELIX A.S., SOLIMAN A.S., KHALID H., et al.: The changing pattern of bladder cancer in Egypt over the past 26 years. Cancer Cause Control, 19: 421-9, 2008.

3- TEAMA A.H., DARWEESH A.N., ABOL-ENIN H.A., et al.: Role of multidetector computed tomography virtual cystoscopy in evaluation of urinary bladder carcinoma. EJRNM, 45: 543-54, 2014.

4- AMIN M.F. and ABD EL HAMID A.M.: The diagnostic accuracy of multidetector computed tomography with multiplanar reformatted imaging and virtual cystoscopy in the early detection and evaluation of bladder carcinoma: Comparison with conventional cystoscopy. Abdominal Imaging, 38 (1): 184-92, 2013.

5- THOENY H.C., TRIANTAFYLLOU M., BIRKHAEUSER F.D., et al.: Combined ultrasmall superparamagnetic particles of iron oxide-enhanced and diffusion-weighted magnetic resonance imaging reliably detect pelvic lymph node metastases in normal-sized nodes of bladder and prostate cancer patients. Eur. Urol., 55: 761-9, 2009.

6- TAKEUCHI M., SASAKI S., ITO M., et al.: Urinary bladder cancer: Diffusion weighted MR imaging-accuracy for diagnosing $\mathrm{T}$ stage and estimating histologic grade. Radiology, 251: 112-21, 2009.

7- AMIN M.B., GREENE F.L., EDGE S.B., et al.: The Eighth Edition AJCC Cancer Staging Manual: Continuing to build a bridge from a population-based to a more "personalized" approach to cancer staging. CA Cancer J. Clin., Mar., 67 (2): 93-9, 2017.
8- EL-ASSMY A., ABOU-EL-GHAR M.E., REFAIE H.F., et al.: Bladder cancer: Diagnosis with diffusion-weighted MR imaging in patients with gross hematuria. Radiology, 251: 415-21, 2009.

9- KOH D.M. and COLLINS D.J.: Diffusion-weighted MRI in the body: Applications and challenges in oncology. A.J.R. Am. J. Roentgenol., 188: 1622-35, 2007.

10- PAPALIA R., SIMONE G., GRASSO R., et al.: Diffusionweighted magnetic resonance imaging in patients selected for radical cystectomy: Detection rate of pelvic lymph node metastases. B.J.U. Int., 109: 1031-6, 2012.

11- YOSHIDA S., KOGA F., KOBAYASHI S., et al.: Diffusion-weighted magnetic resonance imaging in management of bladder cancer, particularly with multimodal bladdersparing strategy. World J. Radiol., 2014.

12- PADHANI A.R., KOH D.M. and COLLINS D.J.: Wholebody diffusion-weighted MR imaging in cancer: Current status and research directions. Radiology, 261: 700-18, 2011.

13- BARSOUM N., TALAAT M., SARAYA S., et al.: Can diffusion-weighted MRI predict the histological grade of urinary bladder carcinoma? Kasr Aliny Medical Journal, 23 (2): 86-95, 2017.

14- AL JOHI R.S., SEIFELDEIN G.S., MOEEN A.M., et al.: Diffusion weighted magnetic resonance imaging in bladder cancer, is it time to replace biopsy? Cent. European J. Urol., 71 (1): 31-37. doi:10.5173/ceju.2017.1427, 2017.

15- WANG H.J., PUI M.H., GUO Y., et al.: Multiparametric3T MRI for differentiating low versus high-grade and category $\mathrm{T} 1$ versus $\mathrm{T} 2$ bladder urothelial carcinoma. AJR Am. J. Roentgenol., 204 (2): 330-4, 2105.

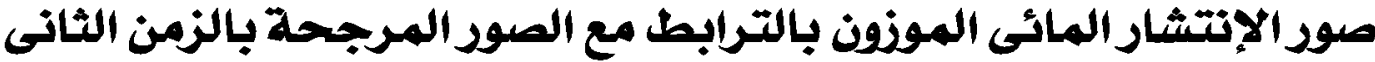

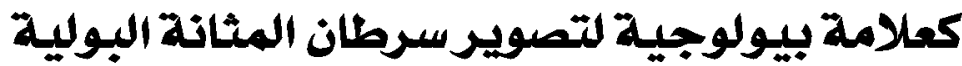

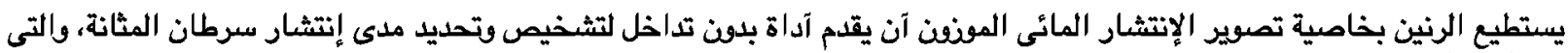

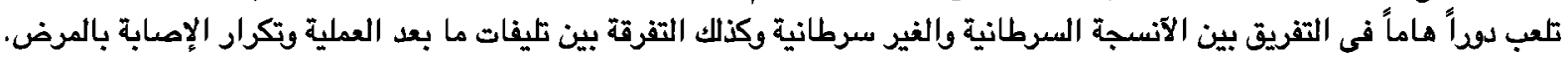

$$
\begin{aligned}
& \text { ويعتبر التصوير بالإنتشار المائى المونفن مساعداً في تصوير الحالات التى يمنع إستخدام الصبغة فيها لإجراء الفحص. } \\
& \text { ويعطى الإنتثار الجزيئي آيضاً معلومات عند ملى خلوية الآنسجة التى يؤثر بلورها على الدرجة الهيستولوجية. } \\
& \text { لقد كثفت الدراسة عن آهمية الإنتثار الجزيئى في التفرقة بين الدرجات الهيستولوجية المختلة. فهناك علاقة عكسية بين معامل الإنتثار } \\
& \text { الظاهرى والدرجة الهيستولوجية. }
\end{aligned}
$$

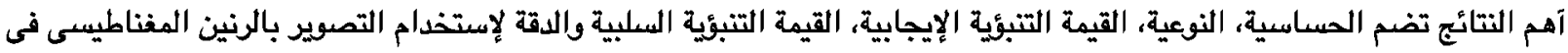

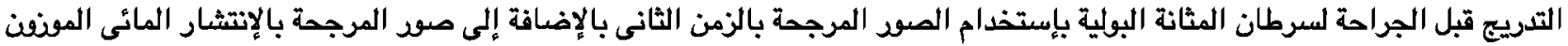

$$
\begin{aligned}
& \text { كانت } \\
& \text { فى الختام، تزيد إضافة الصود المرجحة بالإنتشار المانَى المونفن إلى الصود المرجحة بالزمن الثانى من دقة التدريج السابق لسرطان }
\end{aligned}
$$

